\title{
Poéticas interartísticas: nos limiares da criação literária
}

\author{
Interart poetics: on the literary creation thresholds
}

Doutora em Teoria da Literatura pelo Programa de Católica do Rio Grande do Sul (PUCRS). Porto Alegre RS, Brasil.

http://orcid.org/0000-0001-9996-320X

E-mail: fernanda_etc@hotmail.com

Recebido em: 15/2/2019.

Aprovado em: 28/5/2019.
Publicado em: 16/12/2019.

Endereço:

Av. Ipiranga, 6681, Partenon, Porto Alegre, RS, CEP

90619-900
Fernanda Borges ${ }^{1}$

Pontifícia Universidade Católica do Rio Grande do Sul, Porto Alegre, RS, Brasil.

\section{RESUMO}

A confluência entre as linguagens visual e verbal e o hibridismo dos textos no contato entre palavra e imagem representam uma perspectiva que vem sendo redescoberta nos estudos literários e culturais. Esse diálogo, por mais inovador que pareça ser, não é uma novidade no campo das artes de um modo geral e nem mesmo no campo da literatura visto que, ante uma perspectiva histórica, os limiares artísticos fazem parte da história do conhecimento e da arte. A partir de obras compostas por artigos de jornal, desenhos, fotografias, mapas e por uma disposição textual peculiar ultrapassam a concepção tradicional do que se entende como romance, por exemplo, ao incorporarem, sobretudo, outras manifestações artísticas, o que permite que sejam denominadas como narrativas híbridas e interartísticas, este artigo pretende refletir acerca desse movimento escritural plural e heterogêneo.

Palavras-chave: Poéticas interartísticas. Hibridismo. Limiares da criação literária.

\section{ABSTRACT}

The confluence between visual and verbal communication and the hybridism of texts in the contact between word and image represent a perspective that is being rediscovered in literary and cultural studies. This dialogue, as much innovative as it seems to be, is not a novelty in the field of arts not even in literature since, from a historical perspective, artistic thresholds are part of the History of Knowledge and Art. Hybrid and interartistic narratives are composed of newspaper articles, drawings, photographs, maps and a peculiar textual provision that goes beyond the traditional conception of what is meant by novel. By incorporating, above all, other artistic manifestations, such works are called hybrid and interartistic narratives, and this article intends to reflect on this plural and heterogeneous writing movement.

Keywords: Interart poetics. Hybrid poetics. Literary creation thresholds. 


\section{Ver como se pintasse}

"Há uma imensa diferença entre ver uma coisa sem o lápis na mão e vê-la desenhando-a." (Paul Valéry, em Degas dança desenho)

A

dissolução das fronteiras estanques entre as disciplinas e as artes de um modo geral permite que pensemos as poéticas interartísticas, frutos do "diálogo polifônico entre as várias artes e as respectivas especificidades das retóricas e estratégias de representação, características de cada uma delas" (MACEDO, 2006, p. 11). As categorias se diluem porque não são - e talvez nunca tenham sido - suficientes para analisar e refletir acerca da obra de inúmeros artistas. A necessidade de organização e sistematização deve conviver, desse modo, com a sua frequente reelaboração e com a consciência de sua limitada utilidade, pois as formas de arte e de conhecimento habitam uma zona limiar, a qual permite que os caminhos sejam abertos e compartilhados, não mais fechados e restritos.

O abrigo no limiar é a aceitação de que também existem falências na homologação de uma caminhada absolutizada por uma condição de interioridade ou exterioridade. 0 proteger-se no 'entre' passa a ser uma estratégia de sobrevivência que rechaça as territorialidades fendidas pela arbitrariedade das fronteiras conceituais (BARBERENA, 2014, p. 9-10).

O processo para a criação de uma obra nem sempre obedece a regras e ordens pré-estabelecidas, podendo transitar entre as mais diversas áreas, o que caracteriza seu hibridismo. As fronteiras entre as artes e entre os vários campos do conhecimento se diluem cada vez mais porque, além de considerarem características e categorias específicas de cada área, elas também foram estabelecidas arbitrariamente, como convenções, muitas vezes de modo a postular limites e barreiras para o diálogo entre as manifestações artísticas, por exemplo.

Contrabandear saberes sob um regime limiar de pensamento é afrontar uma potencialidade de divisão epistemológica que busca uma classificação pura entre os diferentes quadrantes do discurso. A necessidade de separação entre as áreas de pesquisa tem se mostrado absolutamente problemática no tocante ao cerceamento de liberdade na criação/teorização acadêmica. Pensado neste sentido, o limite se configura como uma espécie de disfarce inventado para segmentar domínios imaginados por determinada instância de poder. No entanto, as cartografias disciplinares contemporâneas têm se apresentado permeadas por uma vontade de transgressão dos muros obsoletos do saber (BARBERENA, 2014, p. 10-11)

A própria história da arte comprova que não há nada de que ela goste mais que quebrar convenções e se reinventar, em um contínuo jogo de bifurcações, transgredindo tais muros obsoletos de saber. Seja por meio de novos suportes das cavernas às paredes das grandes cidades -, seja por meio de novos modelos estéticos de representação - do figurativo ao abstrato, do romantismo ao realismo -, a arte opõe-se a ela mesma, ao que dizem que ela é. Os movimentos artísticos e estéticos que endossaram instituições de poder e de saber também tinham a característica primordial da arte, que é transgredir. A arte futuristafascista, por exemplo, transgredia o movimento anterior enquanto propunha um novo movimento, diretamente ligado ao poder que se instaurava na Itália.

É interessante refletirmos acerca do fato de que somente se tem a necessidade de estabelecer outras possíveis categorias - como "poéticas interartísticas" ou "obras limiares" - porque outras categorias anteriores, mais rígidas e arbitrárias, foram instituídas para compartimentalizar o conhecimento, a cultura e a arte. Professor da Universidade de Chicago, W. T. J. Mitchell (2005) explica que não existem meios visuais, pois "Todos los supuestos medios visuales, al ser observados más detalladamente, involucran a los otros sentidos (especialmente al tacto y al oído). Todos los medios son, desde el punto de vista de la modalidad sensorial, 'mediosmixtos'” (MITCHELL, 2005, p. 17) ' $^{\text {. A }}$ própria pintura, que seria a primeira candidata a meio visual, envolve uma produção manual, tátil, muitas vezes dada a ver em diversos quadros. Nesse sentido, o autor reflete ainda sobre a arquitetura e a escultura.

La arquitectura no se basa fundamentalmente sobre el ver, sino sobre el vivir y habitar. La escultura es tan evidentemente un arte táctil que

Todos os supostos meios visuais, ao serem observados mais detalhadamente, envolvem outros sentidos (especialmente o tato e a audição). Todos os meios são, do ponto de vista sensorial, meios mistos (tradução nossa) 
parece superfluo discutir sobre ello. Se trata del único de los llamados medios visuales que, de hecho, es directamente accesible para los ciegos (MITCHELL, 2005, p. $19^{3}$.

Logo, não existem meios visuais porque todos os meios são mistos, como também afirma anteriormente Christian Metz, pois “[...] la propia noción de medio y mediación ya implica de por sí una mezcla de elementos sensoriales, perceptivos y semióticos. No hay tampoco ningún medio puramente auditivo, táctil, ni olfativo" (MITCHELL, 2005, p. 20)4

$\mathrm{Na}$ História da Teoria da Literatura, essas aproximações entre as artes podem ser norteadas, sobretudo, a partir de dois conceitos: intertextualidade e interdisciplinaridade. Essas concepções complementam-se ao pensarmos as relações possíveis entre diferentes abordagens e expressões artísticas.

O precursor da discussão acerca do imbricamento de discursos foi Mikhail Bakhtin, que iniciou sua carreira na década de 1920. A partir da designação teórica de intertextualidade, por Julia Kristeva, na esteira do pensamento de Bakhtin, novos caminhos foram trilhados nos estudos literários, pois os conceitos de autoria e de originalidade, por exemplo, foram revistos no âmbito da Literatura Comparada e da Teoria da Literatura, uma vez que a incorporação da tradição literária e a livre menção a outros textos e autores passaram a ser vistas com naturalidade, como constituintes do processo de criação da obra, alterando as tradicionais e inócuas discussões acerca de fontes e influências, as quais estabeleciam na literatura conceitos de hierarquia. A ideia de dependência, decorrente de tais pressupostos, passa a ser anacrônica, pois segundo Carvalhal

[...] se a noção de influência tendia a individualizar a obra, sobrepondo o biográfico ao textual e impondo uma causalidade determinista na produção literária, a intertextualidade, ao designar os sistemas impessoais de interação textual, coletiviza a obra (CARVALHAL, 1993, p. 32).

A arquitetura não se baseia fundamentalmente sobre o ver, mas sobre o viver e habitar. A escultura é tão evidentemente uma arte tátil que parece supérfluo discutir sobre isso. Trata-se do único dos chamados meios visuais que, de fato, é diretamente acessível para os cegos (tradução nossa).

[...] a própria nocão de meio e de mediação já implica uma mescla de elementos sensoriais, perceptivos e semióticos. Não há tampouco nenhum meio puramente auditivo, tátil ou olfativo (Tradução nossa).
Assim toda obra literária se constrói como uma rede de influências e relações com textos literários preexistentes e com sistemas de significação não literários, como as linguagens orais ou a música. Daí a importância de seu estudo: "A verdade literária como a verdade histórica, só pode constituir-se na multiplicidade dos textos e das escritas - na intertextualidade" (JENNY,1979, p. 47).

A partir da ampliação do conceito de intertextualidade, passa-se ao conceito de interdisciplinaridade, que abarca diversos campos das Ciências Humanas (Filosofia e História, por exemplo), e diversas manifestações artísticas (como literatura, música, artes plásticas, fotografia, cinema), áreas em constante diálogo estético e cultural. Assim como os textos literários podem imiscuir-se uns nos outros, o mesmo ocorre com outras disciplinas do conhecimento, com as artes de um modo geral. Desse modo, a partir do diálogo intertextual, interdisciplinar, interartístico, e considerando o hibridismo das linguagens artísticas, é fundamental analisar alguns casos específicos que refletem tais discussões teóricas; pensar sobre obras as quais também já são a narrativa de sua poética.

Ilustrando o hibridismo entre as artes, Paul Valéry, em Introdução ao método de Leonardo da Vinci, analisa e discute o "Possível dum Leonardo, de preferência ao Leonardo histórico" (VALÉRY, 2005, p. 66). 0 poeta, a partir da descrição de procedimentos utilizados por da Vinci, reflete sobre a amplitude do processo de criação do pintor, o qual, segundo Valéry, tinha a pintura como filosofia. 0 Leonardo-Possível é "aquilo que sua história só incertamente depreende" (VALÉRY, 2005, p. 66), ou seja, aquilo que ele também poderia ter sido ou poderia ter feito a partir de outras escolhas e oportunidades. Segundo Jean-Michel Rey (1994, p. 153), "graças ao modo de expressão que 'escolheu', o artista é suscetível de aumentar sua força, de transformar seu possível". Se a pintura foi a arte priorizada por da Vinci, ele seguirá sempre podendo vir a ser o Leonardo desenhista ou arquiteto, como possibilidade e potência. Do mesmo modo, mas respeitando-se as devidas proporções obviamente, Valêncio Xavier, ao escolher chamar algumas de suas obras de "livros", deu-nos inúmeras possibilidades de exposições fotográficas, por exemplo. Ao "escolher ser escritor", neste caso, deu-nos a potência do fotógrafo.

"Leonardo é um pintor: afirmo que tem a pintura por filosofia. Na verdade, foi ele mesmo quem o disse; e fala em pintura como se fala em filosofia; isto é, todas as coisas estão aí presentes" (VALÉRY, 2005, p. 125). Valéry destaca que da Vinci, para pintar, realiza um estudo detalhado que perpassa inúmeros campos do saber, isto é, enfatiza que pintar não é apenas pintar. 
A sua pintura, com efeito, exige sempre dele uma análise prévia e minuciosa dos objectos que pretende representar, análise que não se limita de modo nenhum às características visuais, mas que chega ao mais íntimo ou ao orgânico, à física, à fisiologia, até à psicologia; para que finalmente a vista se prenda, de certa maneira, na detecção dos acidentes visíveis do modelo, os quais resultam da sua estrutura oculta (VALÉRY, 2005, p. 125).

Até que se chegue ao quadro, à obra final, não é apenas com a manipulação das tintas que o artista tem que lidar. A criação envolve inúmeros aspectos do conhecimento, da estética e da subjetividade, portanto, não somente a criação de Leonardo da Vinci é híbrida, mas toda e qualquer criação artística, mesmo que a obra final não o seja". "A análise de Leonardo leva-o a estender o seu desejo de pintar à curiosidade por todos os fenómenos, mesmo os não visuais, pois nenhum lhe parece indiferente à arte de pintar, tal como esta lhe parecia preciosa para o conhecimento em geral" (VALÉRY, 2005, p. 127). Pintura é fisiologia, matemática, arquitetura, psicologia, filosofia, pois, para Leonardo da Vinci, pintar é ter interesse e curiosidade pelo mundo. Paul Valéry, no livro Degas dança desenho, em que escreve sobre Edgar Degas, expõe que o pintor apresentava uma perspectiva semelhante nesse sentido à de Leonardo da Vinci uma vez que "falava sempre de arte científica; dizia que um quadro é o resultado de uma série de operações..." (VALÉRY, 2012, p. 16). Portanto, falar somente de talento e de sensibilidade, por exemplo, mais que prosaísmo, é também ingenuidade. Dando um salto no tempo e no espaço, a relação da pintura com a escritura na obra da escritora brasileira Clarice Lispector também demonstra o quanto as artes podem imiscuir-se na constituição da poética de um artista. Em Clarice Lispector: pinturas, Carlos Mendes de Sousa analisa a importância da pintura para se compreender o processo criativo da autora, bem como a emergência da dimensão visual de sua prosa, ou seja, como essa vertente plástica emana da sua literatura. A partir de cartas, depoimentos, crônicas, contos e romances de Clarice e de outros autores que com ela tiveram contato, além de textos críticos, o diálogo da literatura com a pintura é estabelecido de modo a refletir como a pintura faz-se presente em seus textos e como os

Aqui se trata somente do processo de criação, pois nem todo processo de criação híbrido resultará em uma obra com elementos híbridos, ou seja, em que seja visível e perceptível a presença de outras artes. textos se fazem presentes em suas pinturas - sim, Clarice também pintava. Em Água viva, livro mais emblemático nesse sentido, encontramos uma série de elementos que se reportam a tal relação interartística.

Podemos mesmo aproximar, em termos globais, a escrita de Clarice Lispector de um modelo de pintura não figurativa, onde ocorre uma adequação às descrições de estados interiores. 0 pendor essencialmente abstrato fica bem vincado em passagens de Água viva que se reportam à fixação do incorpóreo; refira-se à insistência nessa vertente abstracionista quando se leem expressões como "pinto ideias", "pinto o indizível", "pinto pintura" [...] (SOUSA, 2013, p. 99).

Assim como a artista pinta pinturas, pinta escrituras, desenha textos, escreve cores e emoções.

A pintura entra no texto, isto é, o texto faz-nos ver a pintura por dentro. A narradora que escreve uma carta ou uma espécie de diário mostra-nos a escrita em ato como pintura. Vemos o processo de elaboração, os esboços, a mistura das tintas, vemos as mãos que mexem com as cores e com os traços e vemos as palavras adquirindo forma, devindo texto (SOUSA, 2013, p. 104).

Pintura e literatura complementam-se, fundindo-se em um só ato. A narradora de Água viva pinta ideias e também pinta pinturas, pois as ideias transmutam-se por meio das tintas e transformam-se em visualidade. No caso de Clarice Lispector, esse diálogo interartístico está presente tanto na constituição de seu processo criativo quanto na de sua poética uma vez que os quadros da autora, embora não sejam do conhecimento do grande público leitor, compartilham características estilísticas de sua prosa literária.

Somos assim conduzidos a um trânsito de leitura que vai dos quadros à obra e que, com o apoio das palavras da autora, retorna às pinturas. Olhamos para os quadros e os quadros são de Clarice. Olhando-os, vemos os livros e, de olhá-los, neles colocamos as nossas projeções, isto é, os nossos próprios olhares de claricianos entranhados (SOUSA, 2013, p. 162). 
A natureza abstrata da maioria de suas pinturas, os temas abordados e os títulos dos quadros (por exemplo, "Eu te pergunto por quê?", "Perdida na vaguidão", "Tentativa de ser alegre", "Medo") remetem-nos aos textos de Clarice e à possibilidade de seus quadros serem trechos que ficaram de fora das edições de seus livros, páginas suprimidas por terem sido escritas à tinta e em um suporte diverso do papel. Pintar ideias, escrever imagens: mais um aprendizado proveniente da obra de Clarice Lispector.

Figura 1 - Clarice Lispector. "Tentativa de ser alegre”, 15 de maio de 1975, óleo e tinta plástica sobre madeira, $30,2 \times 39,7 \mathrm{~cm}$

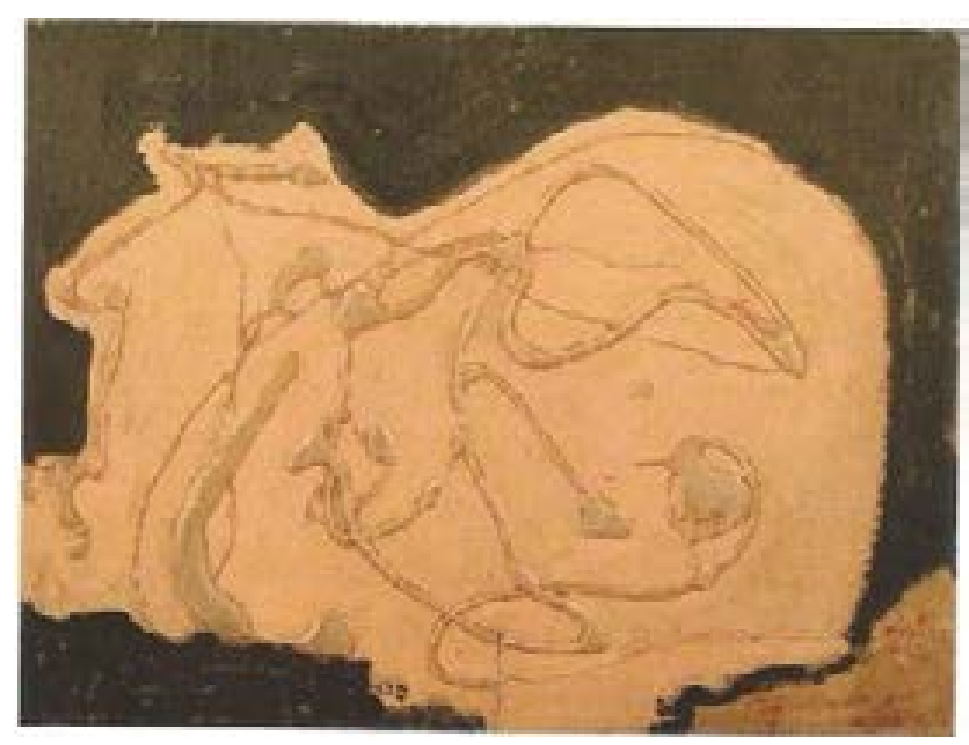

Fonte: SOUSA, 2013, p. 232.

Há uma pluralidade de obras ${ }^{6}$ e de abordagens possíveis para pensarmos o diálogo interartes. Seja do ponto de vista do trânsito por diversos campos do conhecimento e por diversas artes, seja do ponto de vista do processo

Obviamente há diversos casos de artistas com poéticas interartísticas ao longo da história da arte e também criativo, é de fundamental importância que se conceba a obra literária como fruto de diálogos que se encontram em limiares conceituais, no limiar e no contato da página com nossos dedos que a manuseiam.

\section{Trapaceando a língua: os casos de Jonathan Safran Foer e de Valêncio Xavier}

Na aula pronunciada no dia 7 de janeiro de 1977, Roland Barthes discute que a língua também pode ser um instrumento de poder, que tem seu caráter fascista por obrigar-nos a dizer, ou seja, por demonstrar-se coercitiva em muitos momentos. Para ele, a língua desprovida desse caráter autoritário é encontrada na literatura.

Mas a nós, que não somos nem cavaleiros da fé nem super-homens, só resta, por assim dizer, trapacear com a língua, trapacear a língua. Essa trapaça salutar, essa esquiva, esse logro magnífico que permite ouvir a língua fora do poder, no esplendor de uma revolução permanente da linguagem, eu a chamo, quanto a mim: literatura (BARTHES, 2007, p. 16).

0 autor enfatiza o trabalho de deslocamento sobre a língua, o jogo textual estabelecido pela literatura: “[...] o texto é o próprio aflorar da língua, e porque é no interior da língua que a língua deve ser combatida, desviada: não pela mensagem de que ela é o instrumento, mas pelo jogo das palavras de que ela é o teatro" (BARTHES, 2007, p. 16). Logo, se devemos trapacear a língua de seu interior, para que haja renovação e inovação na literatura e, consequentemente, nos estudos literários, e se "toda imagem é, de certo modo, uma narrativa" (BARTHES, 2007, p. 37), por constituir-se enquanto texto e ser permeada pela metalinguagem, trapacear a língua é também narrar fotografando, fotografar narrando. Em Extremamente alto \& incrivelmente perto, do autor estadunidense Jonathan Safran Foer, o menino Oskar Schell nos insere em seu universo visual, utilizando-se de artimanhas infantis, e não por isso menos maduras, em uma

na contemporaneidade. Em termos de poéticas interartísticas, outros casos que mereceriam análise e discussão são os dos brasileiros Lourenço Mutarelli, Nuno Ramos e Verônica Stigger, do lusoafricano Gonçalo M. Tavares, da portuguesa Patrícia Portella, da estadunidense Miranda July e da francesa Sophie Calle, por exemplo. 
tentativa de superação do trauma da perda de seu pai nos incidentes de 11 de setembro. A narração da história ultrapassa a disposição tradicional do que concebemos como romance ao trazer ao leitor fragmentos do álbum de Oskar e algumas fotografias feitas por ele. Tais imagens demonstram como o menino se inscreve no mundo, pois se constituem como uma seleção do narrador daquilo que se inscreve nele. Desse modo, a descrição por meio de palavras é substituída pela inscrição por meio de imagens. "[...] Valéry, em seu 'Discours prononcé pour le centenaire de la photographie', dizia: 'A existência da fotografia nos levaria sobretudo a deixar de querer descrever aquilo que pode, por si mesmo, se inscrever'" (SOULAGES, 2010, p. 270-271). Desse modo, a grafia através de fotos, de imagens, faz-se presente a fim de que se constitua um processo escritural que se inscreva em Extremamente alto \& incrivelmente perto.

Figura 2 - Fragmento do álbum de Oskar Schell
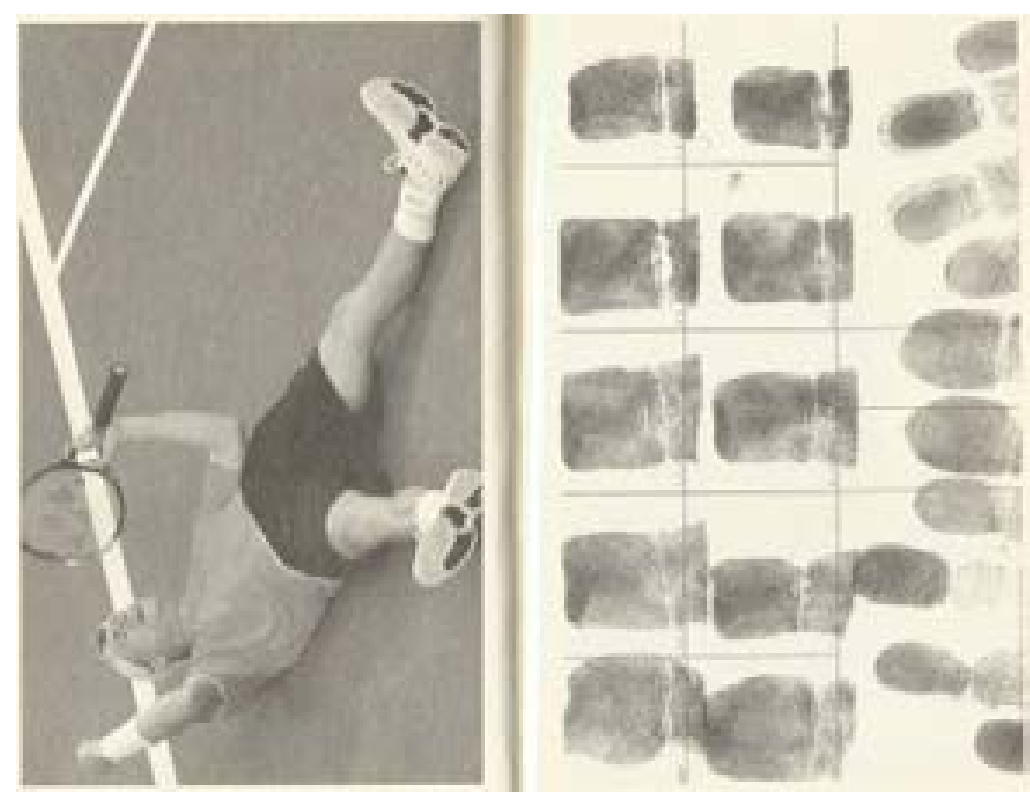

Fonte: FOER, 2006, p. 64-65.

Foto de Chang W. Lee/ New York Times e foto de RandyFaris/ Corbis.
Ainda, o crítico francês François Soulages, refletindo sobre as concepções artísticas do fotógrafo e escritor Denis Roche, explicita que a fotografia também pode constituir um diário:

Para ele [Denis Roche], o trabalho fotográfico torna inútil a literatura autobiográfica e funda a fotografia autobiográfica; é o fim de uma certa prática artística e o nascimento de outra: a fotografia é seu diário íntimo (SOULAGES, 2010, p. 270).

O menino Oskar Schell, em Extremamente alto \& incrivelmente perto, faz da reunião de suas fotografias um diário íntimo e um álbum de família, com suas devidas peculiaridades, elaborando uma narrativa visual. Oskar seleciona, organiza e fotografa imagens para compor o seu álbum, cuja narrativa lhe traz conforto e segurança.

Em "Cartões-postais, álbuns de família e ícones da intimidade", Nelson Schapochnik explica que as fotografias relacionadas à família têm "um valor de culto", por estarem costumeiramente bastante acessíveis aos nossos olhos: em porta-retratos sobre os móveis, em quadros na parede e dentro de nossas carteiras.

Assim como existe um sentido para a preservação e exposição das imagens fotográficas que incidem sobre a memória familiar, certamente deve haver uma lógica interna presidindo a formação e organização das coleções. Parece ser óbvio que não se fotografa a vida toda de uma pessoa ou de uma família. Existem ocasiões propícias ao registro fotográfico, que em última instância remetem para os momentos altissonantes em que se confirma a continuidade e coesão do grupo familiar. 0 que atesta um desejo e uma ação deliberada de registrar aquilo que deve ser objeto de rememoração pela posteridade (SCHAPOCHNIK, 1998, p. 462).

Nelson Schapochnik afirma que a fotografia é a história visual da família. Se apenas uma fotografia já tem características narrativas, embora se constitua, muitas vezes, mais como descrição de uma cena do que propriamente como narração de um episódio, a organização de diversas fotografias em uma certa ordem, em um álbum, dá-lhe efetivamente o atributo de narrativa visual. 
Talvez uma das características de um álbum de família seja o fato de ele se apresentar como uma obra aberta. Embora o guardião da iconoteca familiar se esforce para preservar o acervo e imprimir uma lógica no seu ordenamento, algumas peças podem ser perdidas, outras podem ser acrescentadas e, ao fim e ao cabo, a sua própria morte propiciará uma redistribuição e a "invenção" de uma nova crônica familiar (SCHAPOCHNIK, 1998, p. 463).

Por meios da seleção e da organização de imagens marcantes, o menino narra parte de sua trajetória e de suas memórias, expondo suas brincadeiras favoritas, seus pensamentos e também aquilo que lhe faz falta e lhe dói em segredo. Essa narrativa permanece aberta para novas personagens e novos episódios à medida que o tempo passa, pois, a vida, enquanto narrativa, mesmo que sem novos episódios significantes, será sempre relida, senão reescrita, como é o desejo de Oskar.

A obra do brasileiro Valêncio Xavier também trapaceia a língua e leva a literatura e o livro, como seu suporte, ao delírio e à loucura. Grande parte de suas narrativas conta com desenhos realizados pelo autor, os quais muitas vezes têm caráter de ilustração para o texto escrito.

Figura 3 - Desenho presente em Minha mãe morrendo e o menino mentido
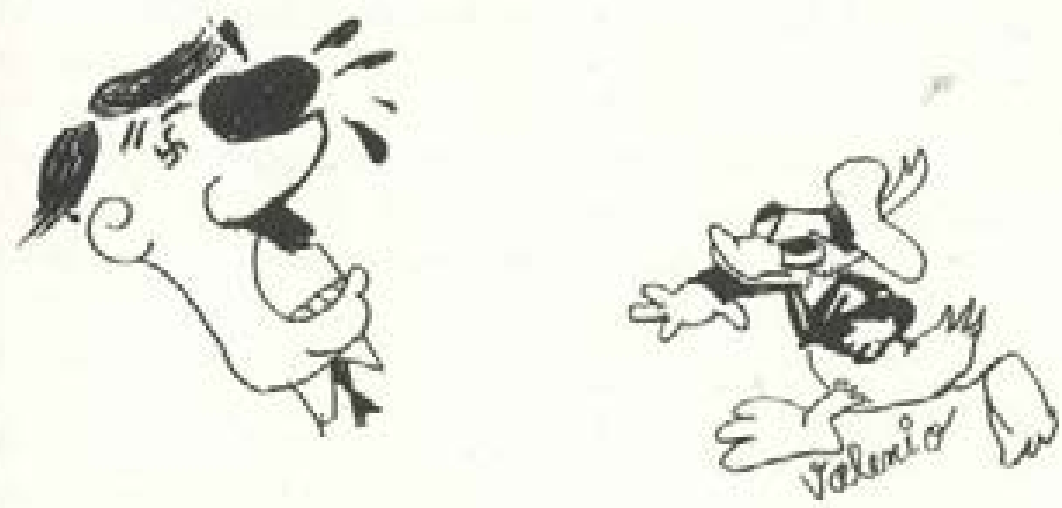

Fonte: XAVIER, 2001, p. 65
Além disso, os traços e rabiscos de Valêncio constituem uma tentativa infantil de escritura, reproduzindo garatujas do menino que desenha ao querer formar um texto.

Figura 4 - Uma das páginas finais de Minha mãe morrendo e o menino mentido

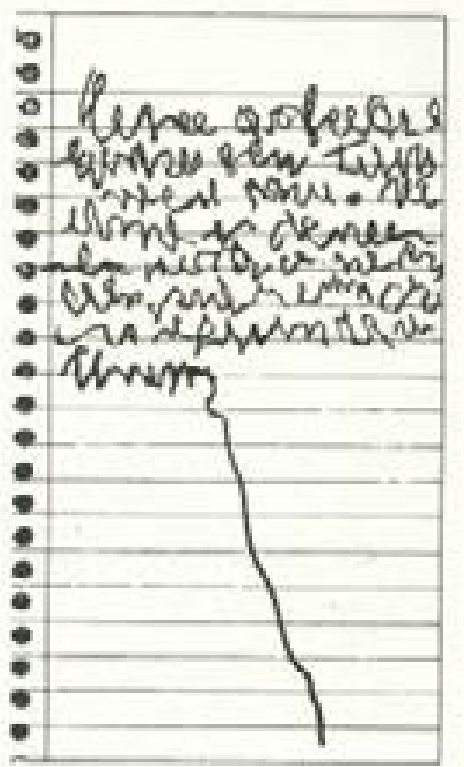

Fonte: XAVIER, 2001, p. 215

Assim como Jonathan Safran Foer, Valêncio Xavier também utiliza fotografias para compor suas narrativas. Imagens fotografadas por ele, por outros artistas, divulgadas em jornais e revistas, ou ainda constituintes de seu acervo pessoal, demonstram o quanto a perspectiva visual e icônica de indivíduos, fatos e eventos é fundamental para sua escritura. A autoria ultrapassa a elaboração e organização somente do texto escrito, o plano tradicionalmente literário e narrativo, para contemplar a criação artística de um modo plural, em 
uma poética interartística. Valêncio Xavier é escritor, desenhista, fotógrafo, contrabandista, artista. Suas obras são consideradas literatura por serem veiculadas em um determinado tipo de suporte, o livro. No entanto, muitas delas poderiam se constituir como exposições e ocupar galerias de arte, por exemplo. Até mesmo o caráter narrativo das obras pode ser relativizado em alguns casos: em Rremembranças de menina de rua morta nua e outros livros, nos livros Sete (7) o nome das coisas e Macao, por exemplo, há um híbrido de poesia com fotografia e relato jornalísticos no primeiro e um híbrido de relato de viagem e roteiro cinematográfico no segundo. E muito mais imagem que texto. Muito mais cenário. 0 mais interessante: essas obras são chamadas de "livro", contudo, poderiam ser denominadas como contos, minicontos, crônicas, mas são livros dentro de livros, pois esse foi o suporte escolhido por Valêncio Xavier. Entre muitos atributos e conceitos, ele escolheu o de escritor, embora sua criação artística comprove que as definições, em alguns casos, podem limitar a leitura e a compreensão, pois o processo criativo encontra-se em uma zona limiar. Talvez a denominação "livro" seja a mais livre de todas uma vez que dentro dele podemos encontrar de tudo um pouco, até algumas histórias.

Figura 5 - "Trecho" de Macao ${ }^{8}$

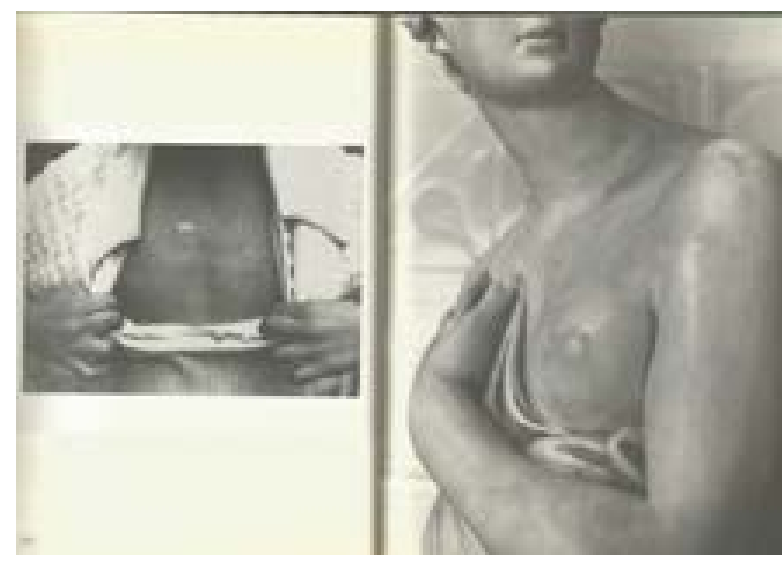

Fonte: XAVIER, 2006, p. 100-101

Fotos de Cláudia Suemi Hamasaki e Valêncio Xavier.
No artigo "O artista an-arquivista: os dispositivos de coleção na arte contemporânea" (2011), Luís Cláudio Costa analisa o trabalho de artistas contemporâneos, em especial o de artistas brasileiros, os quais lidam com materiais colecionados e arquivados para, a partir de uma reinvenção e de uma reelaboração de imagens e objetos, fazer um "reuso" nos termos de Giorgio Agamben no ensaio "Elogio da Profanação" deslocando tais materiais de seus lugares e de suas funções de origem para atribuir-lhes novos significados. 0 autor menciona o trabalho de Paulo Brusky e Rosângela Rennó, mas discute e analisa principalmente as obras de Malu Fatorelli e Leila Danziger. Todos os artistas citados abordam discussões sobre a memória, sobretudo por meio de imagens, assim como Valêncio Xavier e Jonathan Safran Foer, por exemplo. Segundo Luís Cláudio Costa, a cultura e as instituições de poder, inclusive a própria Arte como uma dessas instituições, imobilizam a "memória inventiva", e esse controle exige uma postura artística, pois "a função do artista na sociedade não desaparece. Ao contrário, operando com o sensível na dimensão do arquivo, o artista produz uma visibilidade singular da mediação da subjetividade na cultura" (2011, p. 81). 0 autor também retoma as ideias de Giorgio Agamben para refletir acerca de tal arte contemporânea.

A cultura das comunicações fetichiza a informação conservada em sua imobilização. Tudo pode ser consumido, nem que seja em imagem. Tudo deve tornar-se objeto de posse, mas não deve ser usado. 0 uso desvia a ordem controlada da informação, da memória e da subjetividade. Por isso, torna-se capital a necessidade de resgatar o poder de profanar como política da arte em prol da libertação das imagens, dos objetos e dos discursos da asfixia do arquivo. 0 artista colecionador e an-arquivista age para profanar a imagem do arquivo, bem como seus dispositivos afins na era da cultura midiática centrada em meios de comunicação e informação massivos. Profanar não é negar como se pudéssemos dar fim a esse espaço discursivo. Profanar é permitir o uso singular quando os dispositivos de controle forçam a produção de usuários universais (COSTA, 2011, p. 87).

Ver AGAMBEN, Giorgio.Elogio da profanação. In: Profanações. Trad. Selvino José Assmann. São Paulo: Boitempo, 2007. p. 65-79. 
O autor contrapõe a ideia de arquivo à de coleção, por meio de conceitos de Jacques LeGoff ${ }^{10}$, o qual lê o documento, logo, o arquivo, como objeto e instrumento de poder, e de Walter Benjamin ${ }^{11}$, que apresenta a imagem do colecionador como um grande apreciador de seus objetos, neles podendo fazer modificações. Desse modo, utiliza a concepção de "artista an-arquivista", isto é, aquele que faz um novo uso do arquivo, mais próximo ao do que faz um colecionador ${ }^{12}$. Lidando com imagens documentais oficiais e com imagens que constituem a "memória inventiva" de que fala Costa, Valêncio Xavier e Jonathan Safran Foer também são artistas an-arquivistas nesse sentido. Se as obras de Rosângela Rennó - como Cicatriz (2004) e Fotoportátil (2005), por exemplo -, estão presentes em livros, os quais fazem parte de nossas coleções, as obras de Xavier e de Foer também poderiam gerar exposições e mostras de arte, principalmente por se constituírem como poéticas que deslocam o lugar comum, inclusive por incluírem a cultura de massa como objeto de reflexão, de ironia, de literatura.

As poéticas do arquivo tratam os dispositivos, bem como os materiais e os símbolos da cultura midiática industrial como documentos-signos distanciados do cotidiano prático da vida das pessoas por seu suposto valor de propriedade - intelectual e simbólico, mas também como valor de posse para o consumo individual. 0 gesto crítico e político dessa produção é proporcionar o retorno à vida, ao uso. Trata-se de efetuar deslocamentos que transformem a significação prática dos dispositivos e dos símbolos que eles produzem, realizando a visibilidade da mediação dos mecanismos de conservação que afastam a potência de certos saberes para que não sejam profanados. Usar, nesse contexto, não é simplesmente tornar-se usuário. Enquanto o uso é um modo singular do sujeito e do corpo de relacionar-se com os objetos e dispositivos apropriados, ser usuário é conservar o caráter previsto inerente ao mecanismo que se utiliza (COSTA, 2011, p. 88).

10 LE GOFF, Jacques. Documento/Monumento. In: Enciclopédia Einaudi: Memória - História. Lisboa: Imprensa Nacional; Casa da Moeda, 1984. Volume 1.

${ }_{11}$ BENJAMIM, Walter. Passagens. Belo Horizonte: UFMG; São Paulo: Imprensa Oficial do Estado de São Paulo, 2006.

${ }_{12}$ Aqui não utilizo a ideia de arquivista como aquele responsável por arquivar somente documentos oficiais de instituições de poder.
Dessa forma, o deslocamento estabelecido por meio do diálogo interartes evidencia um jogo escritural plural e heterogêneo que não se limita a usos tradicionais e consagrados, propondo novas leituras reflexões por meio do reuso de diferentes linguagens.

\section{A loucura de poder dizer tudo e de todas as formas}

Diversos conceitos são trapaceados pelas poéticas interartísticas ao serem desafiados por uma escritura limiar, a qual não estabelece distinções e hierarquias entre palavras e imagens. Jacques Derrida, em entrevista concedida em 1989, mas publicada no Brasil somente em 2014, reflete acerca "dessa estranha instituição chamada literatura", a qual permite que se possa "dizer tudo":

Com efeito, nas cadernetas ingênuas ou nos diários íntimos de adolescente a que me refiro de memória, a obsessão pelo proteiforme motiva o interesse pela literatura na medida em que esta parecia ser para mim de modo confuso, a instituição que permite dizer tudo, de acordo com todas as figuras. 0 espaço da literatura não é somente o de uma ficção instituída, mas também o de uma instituição fictícia, a qual, em princípio, permite dizer tudo. Dizer tudo é, sem dúvida, reunir, por meio da tradução, todas as figuras umas nas outras, totalizar formalizando mas dizer tudo é também transpor [franchir] os interditos. É liberar-se [s'affranchir] - em todos os campos nos quais a lei pode se impor como lei. A lei da literatura tende, em princípio, a desafiar ou a suspender a lei. Desse modo, ela permite pensar a essência da lei na experiência do "tudo por dizer". É uma instituição que tende a extrapolar [déborder] a instituição (DERRIDA, 2014, p. 49).

A liberdade de poder dizer tudo, de desafiar convenções textuais a partir do próprio princípio de que tais leis devem ser descumpridas para que a instituição literatura continue sendo literatura, continue sendo arte, é subverter o livro enquanto suporte literário ${ }^{13}$. A possibilidade de dizer tudo transforma-se na 1998. 
possibilidade de fazer tudo: desenhar, montar, fotografar, filmar, mentir e ficcionalizar a própria vida. E isso é tentar transformar a literatura em um mundo melhor: um mundo mais eclético, híbrido, popular, lúdico, divertido, livre. As poéticas interartísticas fazem a literatura tornar-se um lugar novo, uma instituição ainda mais livre, por fazer do leitor o subjétil que foi deslocado e enlouquecido.

\section{Referências}

BARBERENA, Ricardo. Limiarologia: das luzes às soleiras. In: BARBERENA, Ricardo, CARNEIRO, Vinícius (org.). Das luzes às soleiras: perspectivas críticas na literatura brasileira contemporânea. Porto Alegre: Luminara Editorial, 2014. p. 9-31.

BARTHES, Roland. Aula. Tradução de Leyla Perrone-Moisés. São Paulo: Cultrix, 2007.

CARVALHAL, Tania Franco. Literatura comparada e teoria literária: intertextualidade e comunidades interliterárias. Revista TB, Rio de Janeiro, n. 114-115, p. 29-38, jul./ dez. 1993.

COSTA, Luís Cláudio. 0 artista an-arquivista: os dispositivos de coleção na arte contemporânea. Revista Porto Arte, Porto Alegre, v.18, n.30, p.77-90, 2011. https://doi.org/10.22456/2179-8001.29623

DERRIDA, Jacques. Essa estranha instituição chamada literatura: uma entrevista com Jacques Derrida. Tradução Marileide Dias Esqueda. Belo Horizonte: Editora UFMG, 2014.

FOER, Jonathan Safran. Extremamente alto \& incrivelmente perto. Tradução de Daniel Galera. Rio de Janeiro: Rocco, 2006.

JENNY, Laurent. A estratégia da forma. In: JENNY, Laurent et al. Intertextualidades. Coimbra: Livraria Almedina, 1979. p. 5-27.

MACEDO, Ana Gabriela, GROSSEGESSE, Orlando (org.). Introdução. In: MACEDO, Ana Gabriela; GROSSEGESSE, Orlando. Poéticas Inter-Artes: do texto à imagem, ao palco, ao écran. Braga: Universidade do Minho|Centro de Estudos Humanísticos, 2006.

MITCHELL, W. J. T. No existen medios visuales. In: BREA, José Luís. Estudios visuales: La epistemología de la visualidade en la era de la globalización. Madrid: Akal, 2005. p. 17-25.

REY, Jean-Michel. Valéry: Os exercícios do espírito. Tradução de Paulo Neves. In: NOVAES, Adauto (org.). Artepensamento. São Paulo: Companhia das Letras, 1994.
SCHAPOCHNIK, Nelson. Cartões-postais, álbuns de família e ícones da intimidade. In: SEVCENKO, Nicolau (org.). História da vida privada no Brasil: vol. 3. São Paulo: Companhia das Letras, 1998.

SOULAGES, François. Estética da Fotografia: perda e permanência. Tradução de Iraci D. Poleti e Regina Salgado Campos. São Paulo: Editora Senac São Paulo, 2010.

SOUSA, Carlos Mendes de. Clarice Lispector: pinturas. Rio de Janeiro: Rocco, 2013.

VALÉRY, Paul. Degas dança desenho. Tradução Christina Murachco e Célia Euvaldo. São Paulo: Cosac Naify, 2012.

VALÉRY, Paul. Introdução ao método de Leonardo da Vinci. Lisboa: Nova Vega, 2005.

XAVIER, Valêncio. Minha mãe morrendo e o menino mentido. São Paulo: Companhia das Letras, 2001.

XAVIER, Valêncio. Rremembranças da menina de rua morta nua. São Paulo: Companhia das Letras, 2006. 